\title{
Review of "reading in secondary content areas: a language-based pedagogy" by Zhihui Fang and Mary J. Schleppegrell
}

\author{
Shan Zhul
}

Correspondence: szhufromsysu33@ufl.edu

School of Teaching and Learning, College of Education, University of Florida, Gainesville, Florida, USA
Keywords: Content area reading, Functional language analysis, Language-based pedagogy

While books reviewed on disciplinary journals are usually newly published ones, this book is an exception. It was published 9 years ago but remained somewhat unnoticed, like a pearl left in the depth of the ocean. It deserves more attention given the potential pedagogical value it holds to the teaching of reading in secondary content areas and perhaps also writing disciplinary texts.

This book concerns the recent discussion about a shift in secondary literacy education from teaching generic literacy strategies to the teaching of discipline-specific literacy practices. The functional language analysis (hereafter referred to as FLA) approach proposed in the book addresses this call for a shift by going "beyond the strategies often recommended - vocabulary, text structure, key words, and personal responses" (p. iii). The body of the book discusses specific linguistic features of the core secondary subjects: science, history, mathematics and language arts.

The major purpose of this book is to offer teachers "explicit ways to focus on language itself to help students comprehend and critique the advanced texts of secondary schooling" (p. iii). This language focus clearly marks the uniqueness of this book: a detailed description of the application of an approach which concentrates on language itself instead of other elements in teaching reading in different subjects. This linguistic orientation is rooted in the beliefs of Systemic Functional Linguistics (hereafter referred to as SFL) (Halliday \& Matthiessen, 2004), which serves as the theoretic framework of this book. The authors argue that language is the primary medium of learning and instruction. They believe that being able to use this meaning-based metalanguage would enable students to learn content while developing advanced literacy skills (p. iii).

Given the above purpose, it is obvious that the target audience of the book are teachers and teacher educators of core secondary subjects, reading teachers and literacy coaches in middle and high schools, as well as language and literacy scholars interested in reading, language, and literacy in content areas (p. iii). The authors, Professors Zhihui Fang and Mary J. Schleppegrell, are experienced teachers and teacher educators themselves. Both of them have been actively engaged in helping secondary teachers teach reading in content areas and their research has been widely published in the area of literacy education. Other

(c) The Author(s). 2018 Open Access This article is distributed under the terms of the Creative Commons Attribution 4.0 International License (http://creativecommons.org/licenses/by/4.0/), which permits unrestricted use, distribution, and reproduction in any medium provided you give appropriate credit to the original author(s) and the source, provide a link to the Creative Commons license, and indicate if changes were made. 
contributors to the book include Annabelle Lukin (Chapter 5) and Jingzi Huang and Bruce Normandia (Chapter 4). The introduction and description of this language-based pedagogy is based on their savvy teaching experience and rich research expertise on educational study. Traditional reading strategies like predicting, clarifying, visualizing and summarizing, etc., presume students already understand the dense, complex language in academic texts. FLA acknowledges the challenges students confront in reading academic texts. Besides, it goes beyond and adds to these strategies by providing tools "for deconstructing texts, sentence by sentence, to help students process unfamiliar discourse patterns and talk about how meaning is constructed through language choices" (p. 9).

The book adopts a general-to-specific-to-general model for its textual structure. The first chapter gives a brief overview of the book. Framed within the perspective of SFL, chapters 2 to 5 expound the discipline-specific skills and strategies in teaching core secondary subjects: science (Chapter 2), history (Chapter 3), mathematics (Chapter 4), and language arts (Chapter 5). The titles of chapters 2 to 5 imply a contrast between FLA and the traditional ways of analyzing texts in the four core secondary subjects respectively as follows:

Chapter 2 Technicality and Reasoning in Science: Beyond Vocabulary (vs. traditional way of focusing on vocabulary when teaching science)

Chapter 3 Interpretation and Reasoning in History: Beyond Text Structure (vs. traditional way of limiting exploration of historical texts to text structure labels)

Chapter 4 Comprehending and Solving Word Problems in Mathematics: Beyond Key Words (vs. traditional way of narrowing mathematics learning to key words)

Chapter 5 Reading Literary Texts: Beyond Personal Responses (vs. traditional way of restricting language arts to personal responses)

Chapter 6 wraps up the whole book by summarizing the strategies discussed in the body of the book and by indicating other related applications of FLA approach.

Chapter 1 begins with an identification of the challenges confronted by secondary school teachers and students. On one hand, teachers need to "engage an increasingly diverse student body in learning specialized and complex subject matter" (p. 1) but few of them are equipped with the expertise to help their students develop advanced literacy. On the other, many secondary school students are unable to comprehend complex texts and are not prepared "for the challenges they will face in college and workplace reading" (p. 1). A solution to these challenges is offered, i.e. functional language analysis (FLA). In this chapter, the authors propose the term Grammar - the focus of the book - to refer to the language patterns used in each discipline to "develop theories, to engage in interpretation, and to create specialized texts" (p. 2). The introduction of the term Grammar is followed by brief analyses of sample texts taken from the four core secondary subjects to illustrate the specific linguistic features of each discipline. A comparison of traditional reading strategies and FLA is made in order to highlight the advantages of FLA in teaching secondary content area reading. The authors emphasize that content area teachers play an import role in helping students recognize how language works in a specialized way (p. 10). Equipped with the language-based metalanguage, teachers are now prepared to help students develop advanced literacy skills. To make Chapter 1 a more complete introduction to the book, a brief discussion of SFL is desirable and would have better prepared readers for subsequent chapters. The first chapter ends with an overview of the whole book. 
Chapter 2 unfolds as the authors identify four salient features of scientific language: technical vocabulary, abstraction, high density, and tightly knit structure (p. 20-21). Each feature is expounded with examples taken from real textbooks. This chapter also suggests effective ways to tackle the challenges posed to students by these four key features. One of the linguistic features of scientific texts worth mentioning is the tightly knit structure of scientific texts. Scientists use the pattern of thematic progression to create a text that flows from one clause to the next, building a successive explanation or an accurate and coherent account of information or phenomena. Mastery of this feature enables students not only to comprehend the information accumulated and developed in this way in scientific texts but also to learn to organize their ideas in their own writing.

Chapter 3 discusses the strategies FLA offers for teaching and learning history texts. According to the authors, observing history texts from the perspective of FLA enables students "to recognize how language changes as the texts presents different perspectives on history" and teachers "to go beyond generic text structure labels to help students see how historical meanings are constructed in recurring patterns related to the goals and purposes of history instruction" (p. 40). Focusing on the wording that constructs time and cause, attributes agency, and presents judgement and interpretation, the authors carry out the analysis of a sample history text by answering three research questions: How did the author organize this section? What is going on in the text? What is the perspective of the author? In demonstrating how to close read the history text, this chapter shows teachers the varied ways to lead students to identify textual meaning (organization), experiential meaning (content), and interpersonal meaning (stance/perspective), which are the three kinds of meaning SFL is mainly concerned with.

Contrasting with the traditional "key words" approach to mathematic word problems, the alternative way presented in Chapter 4 from the perspective of FLA helps students recognize the connection between the language patterns used in a word problem and the mathematic knowledge to be applied in tackling it (p. 66). The authors are cautious in striving for a balance between the effectiveness of linguistic knowledge and the importance of mathematics knowledge. This balance is especially important and helpful for language learners. Those who have enough mathematic knowledge may be challenged by the language, and others may have good control of language but are lack of basic mathematic knowledge. Both are indispensable to solving mathematical word problems. It is pointed out that FLA is most helpful in addressing the first two questions in the seven-question-problem-solving heuristic, i.e. in identifying tasks and key information (pp. 66-67). In other words, the mood analysis (whether the problem asks questions or makes commands) helps students identify the task presented in the problem. The clause analysis enables students to identify the key information in the text and connect it to mathematical concepts.

Compared with science and mathematics, language arts seem to be the "right" place to talk about linguistic analysis. In Chapter 5, Annabelle Lukin, following the points of Ruquaya Hasan (1985), a famous systemic functional linguist, argues that it is misleading to search for "the language of literature". Instead, teachers should look at "language in literature" when analyzing literary texts for it is the language choices that gives a literary work its meaning and its force. Using a poem by Edna St. Vincent Millay as an example, Lukin illustrates how to help students recognize these language choices and how these language choices work in a literary text. The illustration is expanded along 
investigation of three kinds of language patterns: the patterns in the graphology and sound systems that reveal the rhetorical and textual organization; the semantic chains in the poem that show the patterns of meaning; clauses that illuminate further the interpersonal, experiential, and textual meaning. Lukin suggests that FLA provides a more powerful tool that enables both teachers and students to support their interpretations with textual evidence.

Chapter 6 reiterates the contribution FLA makes to the teaching of reading in secondary content areas. The authors suggest that all teachers should read all of the chapters in the book, regardless of their subject area, to get a full picture of how texts work in each discipline. The interrelationship across different subjects is also highlighted in this chapter. To make FLA approach more accessible to teachers, a comparison of the functional grammar terms and the traditional grammatical word class categories is provided. As for the application of FLA in classroom instruction, the chapter offers a summary of the basic steps of infusing text analysis and discussion into content area instruction. At the end of the chapter, the authors make suggestion for further application of FLA approach, such as in evaluating the difficulty level of students' reading materials and students' academic writing.

The book usefully contains sufficient tables and figures, which either achieve visual impact to enhance understanding, or communicate information more effectively than cluttering up texts. For example, Fig. 2.2 on page 33 presents the zig-zagging pattern of thematic progression in scientific writing discussed in Chapter 2. This figure achieves the effect that pure text can hardly make. Table 2.1 on page 37 in the same chapter summarizes the key discourse features of science, the grammatical resources that realize these features, the language analysis strategies for helping students recognize the meaning in these features, and sample classroom-based activities for engaging students in language analysis and exploration. The table presents information in an organized manner. Similar examples can be found in other chapters, too.

Another merit the book possesses is the precise and accurate language and accessible writing style it uses. Additionally, while the authors directly and forcefully present their solution to the challenges both secondary school teachers and students are facing, they still recognize the usefulness of traditional approaches and point out that the traditional ways of teaching reading are not good enough and thus a new approach is needed. In this way, the authors make the potential audience more willingly to accept their point of views and be more open to FLA approach.

In addition, the book is well-organized with a brief introduction in Chapter 1 and a concise summary in Chapter 6, with Chapters 2 to 5 constituting the body of the book. In all these four body chapters, there is a section of "Working with students" discussing especially the application of FLA in classroom instruction. This section not only makes the body chapters coherent but also supplies a space for connecting theory with practice.

As pointed out at the beginning of this review, the contribution of this book to the teaching of reading in secondary content areas is undervalued. This book was published 2 years before Common Core State Standards (CCSS) came into being. CCSS is a set of clear college- and career-ready standards for k-12 students in the United States that details what they should know in English language arts; literacy in history/social studies, science, and technical subjects; and mathematics at the end of each grade. The authors had already foreseen the importance of helping students comprehend disciplinary texts 
"of steadily increasing complexity as they progress through school" (National Governors Association Center for Best Practices (NGA) and Council of Chief State School Officers (CCSSO), 2010, p.2). Other instances of their foresights are found in the suggestions proposed in Chapter 6 of using FLA approach in the discussion of text complexity and teaching writing, which are under heated debate in recent years. The language-based analyses presented in the book enables students to recognize the linguistic features of the four core secondary subjects and to use them in distilling information from scientific texts; seeing "how historical meanings are constructed in recurring patterns related to the goals and purposes of history instruction" (p. 40); identifying the mathematical concepts, procedures and principles needed to solve a word problem; and constructing interpretations of and accumulating evidence toward the theme of a literary text. This ability is exactly what CCSS is calling for: being able to read complex secondary texts "with an appreciation of the norms and conventions of each discipline" (National Governors Association Center for Best Practices (NGA) and Council of Chief State School Officers (CCSSO), 2010, p. 60).

To sum up, what makes this book distinctive from other books on the same topic is its highlighting of the linguistic features of the four core subjects and its focus on the application of FLA in evaluating content area texts and analyzing how meaning is generated in those texts.

Although the authors claim that "the language for talking about language" provided by FLA is "accessible even to those without a background in language analysis" (p. 104), the load of functional concepts is still challenging to readers who are not familiar with SFL. Should there be a separate chapter with a brief introduction to the key terms of SFL, the accessibility of the book would be considerably increased.

However, the book covers only the core subjects in secondary content areas: Science, History, Mathematics and English Language Arts. It is hoped that a revised edition of the book would encompass discussions of the application of FLA in the teaching and learning of more content area subjects.

The weaknesses of the book do not undermine the contributions the book makes if teachers and students apply the approach FLA in their disciplinary literacy practices. Its unique features determine its value in the teaching and learning of the subject matters in secondary content areas.

\section{Abbreviations}

CCSS: Common core state standards; FLA: Functional language analysis; SFL: Systemic functional linguistics

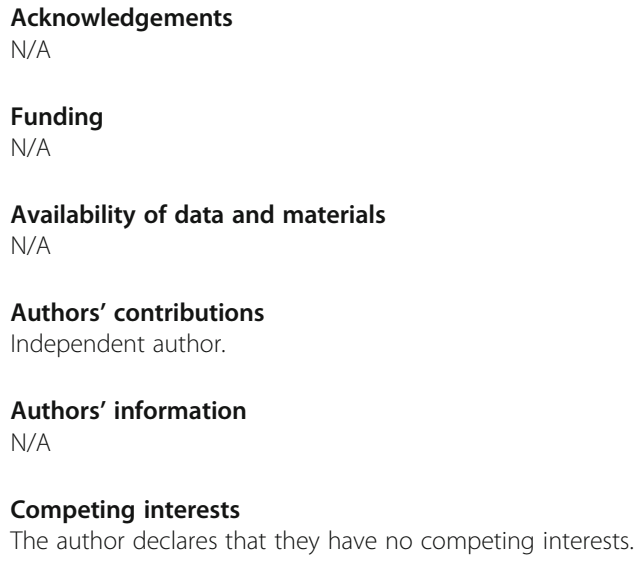




\section{Publisher's Note}

Springer Nature remains neutral with regard to jurisdictional claims in published maps and institutional affiliations.

Received: 1 September 2017 Accepted: 11 January 2018

Published online: 17 January 2018

\section{References}

Halliday, Michael, and Christian Matthiessen. 2004. An introduction to functional grammar. 3rd ed. London: Arnold.

Hasan, Ruqaiya. 1985. Linguistics, language and verbal art. Geelong, Australia: Deakin University Press.

National Governors Association Center for Best Practices (NGA) and Council of Chief State School Officers (CCSSO).

2010. Common Core state standards for English Language Arts \& Literacy for history/social studies, science, and

technical subject. Washington DC: NGA and CCSSO.

\section{Submit your manuscript to a SpringerOpen ${ }^{\circ}$} journal and benefit from:

- Convenient online submission

- Rigorous peer review

- Open access: articles freely available online

- High visibility within the field

- Retaining the copyright to your article

Submit your next manuscript at $\gg$ springeropen.com 